\title{
SUSTAINABLE METROPOLITAN TRANSPORT: STAKEHOLDERS' OBJECTIVES IN THE GREATER SANTOS METROPOLITAN AREA IN BRAZIL
}

\author{
LUIZ FERNANDO DE MELO CORREIA \& MARIA LUCIA GALVES \\ State University of Campinas (UNICAMP), Brazil.
}

\begin{abstract}
Promoting sustainable transport in metropolitan areas is a complex problem due to the large number of stakeholders involved. These stakeholders often have conflicting objectives, and each community absorbs sustainability-related concepts in a different way depending on the local context. In this environment, it is crucial to understand the perspectives of the different stakeholders and to seek out a process capable of effectively supporting an understanding of the problem and thereby propose sustainable transport options. Based on the requirements for sustainable transport and through the involvement of the various stakeholders, a process was created to meet their fundamental objectives in a way that makes possible the application of this process in any metropolitan area. The proposal was applied to the Greater Santos Metropolitan Area, known locally as the Baixada Santista, an important metropolitan coastal area in southeastern Brazil. Thirty-nine fundamental objectives were established. They were organized into environmental, social, and economic categories that reflect the multifaceted nature of the process used to determine the various stakeholders' objectives regarding the sustainability issues of metropolitan transportation.

Keywords: Involvement, Metropolitan transportation, Objectives, Sustainability, Transportation planning
\end{abstract}

\section{INTRODUCTION}

Planning is a crucial step in any development initiative, including one focused on urban sustainability [1]. In metropolitan areas, the gravity and complexity of these issues require innovative approaches and solutions. Fragmentation of the management structure of the various local governments within a given region weakens the policymaking and planning processes [2]. This factor leads cities to disregard transportation issues of the region and to implement solutions only at the municipal level. There is a consequent increase in the problems generated by transportation, such as higher numbers of vehicles on the road, congestion, and increased travel times [3]. Another difficulty is the coordination between urban planning and transportation planning, generally a complex relationship due to the specificities of regional and metropolitan transportation projects. Transportation planning often emphasizes the central regions of cities and neglects the outskirts [4].

Within this context, transportation planners identify the need for greater coordination and collaboration among stakeholders as a key step in addressing transportation network planning issues and sustainability initiatives [5]. The European Environment Agency [6] notes that transportation planning requires long-term vision. Solutions require proposals based on substantial input from the public and other stakeholders, and the objectives should reflect the local situation. On the other hand, some approaches for more sustainable transport systems are so ambitious that they do not provide any guidance on how to mediate or balance competing objectives. Moreover, they do not portray a clear idea of how the system's objectives interact [7]. The difficulty in achieving these objectives is even greater in metropolitan areas, since cities within a given region exhibit different characteristics, strategies, and policies regarding transportation planning, including stakeholders' views on sustainability [8].

Some authors have developed methods that seek to reconcile the conflicting objectives involved in the development of sustainable transport. Examples include Yedla and Shrestha 
[9], who established scenarios and options for transportation systems for the city of New Delhi, India; Silva et al. [8], who defined the dimensions of sustainable mobility in different Brazilian regions by observing stakeholders' objectives; and Jones et al. [10], who integrated stakeholders' views at different levels within several hierarchies to address the general concepts of sustainability. Other planning models already consider the importance of public participation in the process, such as the Plans de Déplacements Urbains (PDUs) used in France since the 1980s [11] and the Sustainable Urban Mobility Planning (SUMPs) developed by the European Commission in the last two decades [12].

However, there is a need for methodology that can be applied to any metropolitan area while respecting the characteristics unique to each. Thus, this study sought to develop and apply a process to determine various stakeholders' objectives regarding sustainable transport in a specific metropolitan area. To clarify the concepts required to develop the proposal, the specificities of sustainable metropolitan transportation will be analyzed in Section 2. In Section 3, the methodology will be presented and divided into two stages: theoretical background information on Keeney's approach [13], which supports the identification of stakeholders' values in the case of metropolitan sustainability, and the description of a process to determine stakeholders' objectives regarding sustainable metropolitan transport. In Section 4, the process will be applied to the Greater Santos Metropolitan Area, known locally as the Baixada Santista. Section 5 contains discussions on the results, followed by the conclusions.

\section{SUSTAINABLE METROPOLITAN TRANSPORT}

Once countries began to prioritize sustainable development in the 1980s, the sustainability of infrastructure became an area of interest in education and research, which began to consider its practical applications [14]. The concept of sustainable transport emerged when the transportation sector attempted to apply these concepts of sustainability and mitigate its negative aspects [15]. According to Litman [16], the term "sustainable transport" is a logical continuation of the concept of sustainable development and is used to describe modes of transportation and planning systems that are consistent with broader sustainability concerns. It interconnects with the concept of sustainable mobility, which addresses, in addition to modal, the planning and regulation of land use [17]. Many cities around the world are seeking to establish more sustainable urban transportation systems in order to reduce accidents, congestion, and air and noise pollution; these changed systems also have the ability to improve social interactions by reducing the injustices created by contemporary transportation systems [18]. In specific metropolitan areas, researchers have studied the measures necessary to promote sustainable metropolitan transport [19-22]. Nevertheless, few metropolitan institutions' plans have considered the impact of transportation on environmental, social, and economic aspects, which are essential in a sustainable transport system [23]. The first requirement for achieving sustainable transport is to determine the sustainability objectives, or the environmental, social, and economic objectives applied to sustainable transport [24-26]. Table 1 summarizes the main objectives of sustainable transport.

The transportation planning process in complex environments such as metropolitan areas must involve the local community in addition to experts and politicians [27]. The second requirement for sustainable metropolitan transport is public involvement, since decisions on this matter directly impact the community [28, 29]. The third requirement represents both public policy and planning measures. Researchers propose a series of public policy measures for the development of sustainable transport, which include technological, behavioral, spatial, and economic factors, as well as physical planning and supply management [25, 30-33]. 
Table 1: Objectives of sustainable transport. (Source: [24-26])

\begin{tabular}{lll}
\hline Environmental & Social & Economic \\
\hline Use Clean Energy & Enable Equal Access & Be Financeable \\
Reduce Waste & Improve Public Health & Induce Economic Development \\
Save Energy Resources & Be Safe & Be Efficient \\
\hline
\end{tabular}

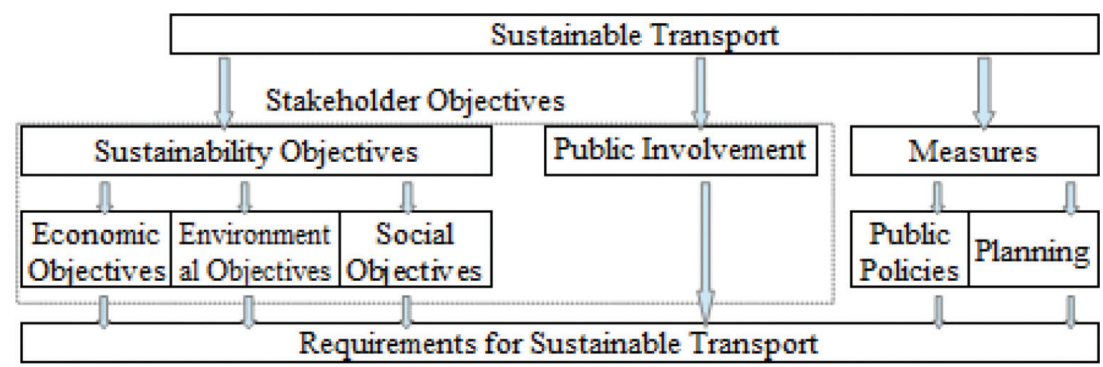

Figure 1: Requirements for sustainable metropolitan transportation.

Others researchers focus on the importance of planning for the development of sustainable transport. Figure 1 presents a flowchart that outlines different stakeholders' objectives regarding these three requirements $[25,26]$.

The first two requirements are the foundation for determining stakeholders' objectives and are the focus of this study as they are a fundamental step in the process of planning sustainable metropolitan transportation. The third requirement can be used in future analyses in the discussion of sustainable metropolitan transport options, which also depend on an understanding of the objectives.

\section{METHODOLOGY}

\subsection{Background}

Given the variety of stakeholders involved in the problem of passenger transportation in metropolitan areas, it is a complex task to reconcile each of their priorities in the establishment of sustainable metropolitan transport. Thus, it is important to adequately structure the problem to ensure public participation and to attempt to determine the viewpoints of the various stakeholders involved. One of the approaches to structuring problems, known as value-focused thinking, was proposed by Keeney [13]. The values of the stakeholders in a decision-making problem can be expressed through objectives separated into means objectives and fundamental objectives, which are structured in a way that illustrates the relationships between all of the objectives. According to Keeney [13], Belton and Stewart [34], Galves [35], and Montibeller et al. [36], structuration phases begin with identification of the decision situation and characterization of the decision-making context. A decision situation arises through the normal course of events or actions and requires a decision. It may be seen as a decision problem or as an opportunity [13]. A decision problem occurs when there is a need to do something about a situation that is not satisfactory [34]. A decision opportunity must be identified by the decision maker rather than anticipated by third parties or outside events. Once the decision 
situation has been identified, the decision-making context must be characterized. The decision-making situation can be characterized by the following elements: decision level, geographical limits, temporal limits, and stakeholders. The decision level can be strategic; it includes policies, plans, and programs, or it may refer to a specific project. The geographic and temporal limits define the space and the time horizon considered in the study [35].

Even if a clearly identified individual is responsible for the decision, it is ultimately the result of interactions between various stakeholders. For Roy and Boyssou [37], a stakeholder in a decision-making process is an individual or a group of individuals who directly or indirectly influence the decision. According to Belton and Stewart [34], stakeholders include decision makers, clients, sponsors, facilitators, and even potential saboteurs. Structuring allows these various stakeholders to develop a common understanding of the problem. The facilitator's role in structuring becomes essential when there are several individuals or groups. Keeney [13] defines the facilitator as an independent analyst who has the skills and impartiality to assist the decision maker. According to Montibeller et al. [36], the facilitator's work has two fundamental aspects: first, the facilitator must help the group explicitly articulate individual interpretations of the decision problem and work together to produce a model that adequately captures its complexity; second, the facilitator must challenge individuals' points of view, values, and beliefs about the problem under analysis in order to promote new knowledge.

Once the decision-making context has been characterized, the stakeholders' objectives must be identified. Keeney [13] distinguishes between fundamental objectives, which represent the aspects that the stakeholders consider essential in the problem under study, and means objectives, which help them reach those objectives. Individual or group interviews with the different stakeholders are necessary in order to identify the objectives. In the interviews, Keeney [13] proposes the use of the following tools: a wish list; alternatives; problems and difficulties; objectives, constraints, and guidelines; different perspectives; strategic objectives; generic objectives; the structuring of objectives; and the quantification of objectives. The answers form a list of objectives that need to be separated into means objectives and fundamental objectives. For each objective, the stakeholders are asked the following question: "Why is this objective important in the context of this decision?" Objectives that are important in their own right are the fundamental objectives, and the others are the means objectives. To be useful in the decision-making process, it is important that the set of core objectives be essential, controllable, complete, measurable, operational, specific, non-redundant, concise, and comprehensible.

Once identified, the fundamental objectives are detailed and organized into a hierarchy that represents the structure of the various stakeholders' values. The top-level fundamental objectives in the hierarchy are defined by the set of objectives directly below, and there must be at least two lower-level objectives attached to any higher-level objective. In this way, the hierarchies of fundamental objectives have a clear and simple ordering. Whether the lower-level objectives provide an exhaustive characterization of the higher-level fundamental objective must be confirmed. The creation of the hierarchy of objectives should continue at lower levels until attributes can be found to measure these objectives. The hierarchy of fundamental objectives has several advantages for specifying values: it helps identify missing objectives, it facilitates identification of redundant objectives, the highest levels allow for general concerns to be easily identified, and the lower levels allow for easier identification of attributes.

\subsection{Process for structuring stakeholders' objectives}

First, it is important to characterize the context of the decision by considering the local geography, population, and modes of transportation. At this stage, the stakeholders involved in 
the transportation of passengers in the region under analysis must also be identified. For identification, we observed the requirements for sustainable transport and the Keeney methodology [13], which relates the degree of stakeholder power and interest in solving the problem. These stakeholders include specialists from local city halls, state-run and private transportation companies, government departments or agencies controlling regional transportation, environmental agencies, local representatives, drivers, and pedestrians as well as the general population. Among the stakeholders, the decision maker can be an internal or external agent who may or may not be part of the government and who has the power to promote and interest in promoting sustainable metropolitan transport in the region. It is important that the decision maker choose a facilitator, preferably someone who is familiar with the concepts of sustainable transport and who has easy access to the other stakeholders. Once the stakeholders and the facilitator have been defined, the interview stage follows. The type of interview used herein is unstructured. In this case, a small report must be made on the topic of sustainable transport in order to determine the elements relevant to the various stakeholders involved [38]. The plan is to use a focused interview with some unguided features. In a purely focused interview, some of the aspects not addressed by the interviewer can be restricted. If it were merely undirected, the interviewee could begin to focus on topics not relevant to the problem under study.

After presenting a short text on the concepts of sustainability and the features of sustainable transport, three questions are asked of the stakeholder being interviewed:

1. What are the worst aspects of passenger transportation in the metropolitan area?

2. What are the best aspects of passenger transportation in the metropolitan area?

3. Based on the concepts of sustainability, what aspects could be implemented and what are the possible difficulties?

As presented in the previous section, the initially identified objectives should be separated into means objectives and fundamental objectives. Fundamental objectives should be organized according to the three main types of sustainability objectives: environmental, social, and economic. Individual hierarchies are validated by the stakeholders themselves. A joint hierarchy must then be presented again for validation on an individual basis. Individual validation of the joint hierarchy is important for the stakeholders to reflect, and if necessary to add, possible objectives that had not been previously considered. Once the hierarchy validation stage has been completed, a conciliation meeting should be held. In this conciliation meeting, the facilitator should encourage a discussion among the various stakeholders in order to deepen their knowledge on the subject, to make possible adjustments in the joint hierarchy, and to obtain the final validation. The process proposed herein is described in Table 2.

Table 2: Process for structuring stakeholders' objectives.

\begin{tabular}{llll}
\hline Step & Activity & Step & Activity \\
\hline 1 & Characterization of Context & 6 & Creation of Individual Hierarchies \\
2 & Identification of Stakeholders & 7 & Validation of Individual Hierarchies \\
3 & Choice of Facilitator & 8 & Creation of Joint Hierarchy \\
4 & Obtaining Objectives & 9 & Validation of Joint Hierarchy and \\
5 & Definition of Fundamental Objectives & & Obtaining the Final Hierarchy \\
\hline
\end{tabular}




\section{APPLICATION OF THE PROCESS TO THE GREATER SANTOS METROPOLITAN AREA}

Based on the process for determining stakeholders' objectives in a given metropolitan area, the application of this process to the Greater Santos Metropolitan Area (known locally as the Baixada Santista) is presented. This region was chosen due to the diversity in its modes of transportation, the presence of large areas of environmental preservation, the presence of the largest port in Latin America, and a high ownership rate of motor vehicles for individual use (automobiles and motorcycles), which cause a series of negative effects.

Step 1: The Baixada Santista, Fig. 2, is formed by nine cities and has a total population of $1,781,620$ inhabitants [39]. The intense traffic generates high rates of accidents and congestion. The metropolitan public transport system is complex and is controlled by both public and private agencies. The main motorized systems are the highway (bus), the light rail system, and the waterway system in addition to automobiles and motorcycles [40].

Step 2: The stakeholders were chosen because of their involvement with transportation issues in the Baixada Santista, including those with a higher degree of interest and/or decision-making power [13]. Through an analysis of sustainability requirements and transportation techniques, stakeholders representing the users and the population of the region were identified. Once all of the stakeholders were listed and after several attempts, support was obtained from all but one of the local city halls.

Local Governments: City of Santos, Guarujá, Bertioga, Cubatão, São Vicente, Praia Grande, Itanhaém, Mongaguá, Peruíbe; State Governments: Metropolitan Urban Transport Company (EMTU), Area Highway Development Agency (DERSA), Greater Santos Metropolitan Area Development Council (CONDESB-AGEM-BS), São Paulo State Environmental Agency-Greater Santos Metropolitan Area Branch (CETESB-BS); Federal Government: Brazilian Institute of Environment and Renewable Natural Resources (IBAMA); and Others: The Brazilian Cyclists Association (ABC)-Users of Non-motorized Transportation, ResidentsNeighborhood Community Councils of Santos, Public Transportation Users-Neighborhood

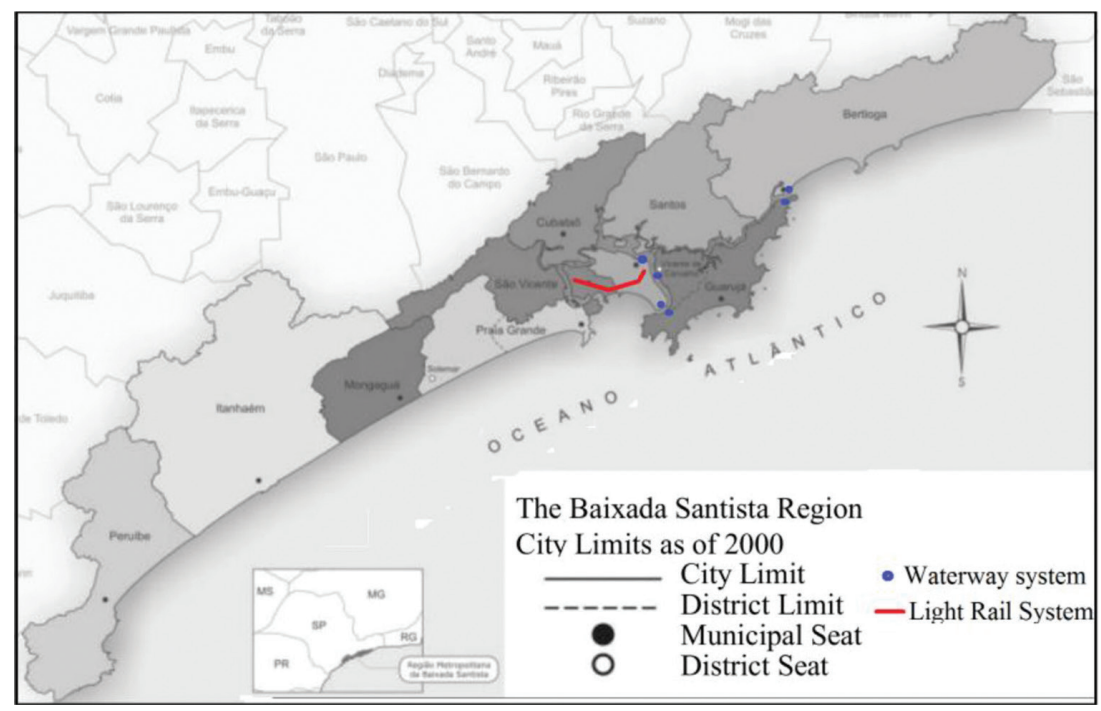

Figure 2: The Greater Santos Metropolitan Area. Source [40] 
Community Councils of Santos, Transportation Operators-Piracicabana Bus Company/ Mobility Consortium, Residents-Association of Committees and Municipal Councils of Bertioga, Public Transportation Users-Association of Committees and Municipal Councils of Bertioga.

Step 3: In this study, the first author of the paper acted as facilitator.

Step 4: During the interview, a short text on the concepts of sustainability and sustainable transport was presented. After this short presentation, the following questions were asked(1) What are the worst aspects of passenger transportation in the Baixada Santista Metropolitan Region? (2) What are the best aspects of passenger transportation in the Baixada Santista Metropolitan Region? (3) Based on the concepts of sustainability, what aspects could be implemented and what are the possible difficulties? Responses are annotated sequentially, so that the objectives can be explored, where they may refer to means objectives and fundamental objectives, which must be separated.

Step 5: For each objective obtained in step 4, the stakeholders are asked the following question: "Why is this objective important in the context of this decision?" Objectives that are important in their own right are the fundamental objectives, and the others are the means objectives. The final result, with 39 fundamental objectives, can be seen in Table 3 .

Table 3: Fundamental objectives.

\begin{tabular}{|c|c|c|c|}
\hline \multicolumn{3}{|c|}{ Fundamental Objectives } & Stakeholders \\
\hline \multicolumn{3}{|c|}{ Reduce Travel Time } & $1,3,4,5,6,7,8,9,10,11,12$ \\
\hline \multicolumn{3}{|c|}{ Reduce Fares } & $1,3,4,5,6,7,8,9,10,11,12$ \\
\hline \multirow{3}{*}{\multicolumn{2}{|c|}{ Comfort }} & Average Age of Vehicles & $1,3,4,5,6,7,8,9,10,11,12,14$ \\
\hline & & Type of Seating and Flooring & $1,3,4,5,6,7,8,9,10,12,14$ \\
\hline & & $\begin{array}{l}\text { Air Conditioning and Enter- } \\
\text { tainment }\end{array}$ & $1,3,4,5,6,7,8,9,10,11,15$ \\
\hline \multicolumn{3}{|c|}{ Increase Free Areas } & $8,10,12,13,15$ \\
\hline \multirow{3}{*}{\multicolumn{2}{|c|}{ Guarantee Safety }} & Reduce Accidents with Users & $3,4,6,7,8,9,10,11,16,18,20$ \\
\hline & & Reduce Traffic Accidents & $3,4,5,7,8,9,10,11,13,15,18$ \\
\hline & & Increase Personal Security & $8,9,14,15,16,17,20$ \\
\hline \multirow{3}{*}{\multicolumn{2}{|c|}{ Reliability }} & Punctuality & $1,3,4,6,9,10,11,12,13,15,20$ \\
\hline & & Frequency & $1,3,4,5,6,9,10,11,12,14,20$ \\
\hline & & Guarantee Complete Trips & $9,10,11,13,18$ \\
\hline \multirow{2}{*}{\multicolumn{2}{|c|}{ Guarantee Health }} & Reduce Stress & $1,3,5,10,11,12,13,14,15,17$ \\
\hline & & Increase Physical Activity & $5,8,15$ \\
\hline & $\begin{array}{l}\text { Ensure Equity of } \\
\text { Access }\end{array}$ & $\begin{array}{l}\text { Accessibility to Users with } \\
\text { Special Needs }\end{array}$ & $3,6,7,10,12,14,16,17,18,19,20$ \\
\hline \multicolumn{3}{|c|}{ Be Accessible to Other Users } & $3,6,7,8,10,15,16,17,18,19,20$ \\
\hline \multirow{2}{*}{. } & \multicolumn{2}{|c|}{ Preserve Historical Heritage } & 13,14 \\
\hline & \multicolumn{2}{|c|}{ Reduce Urban Segregation } & 10 \\
\hline
\end{tabular}


Table 3: (Continued)

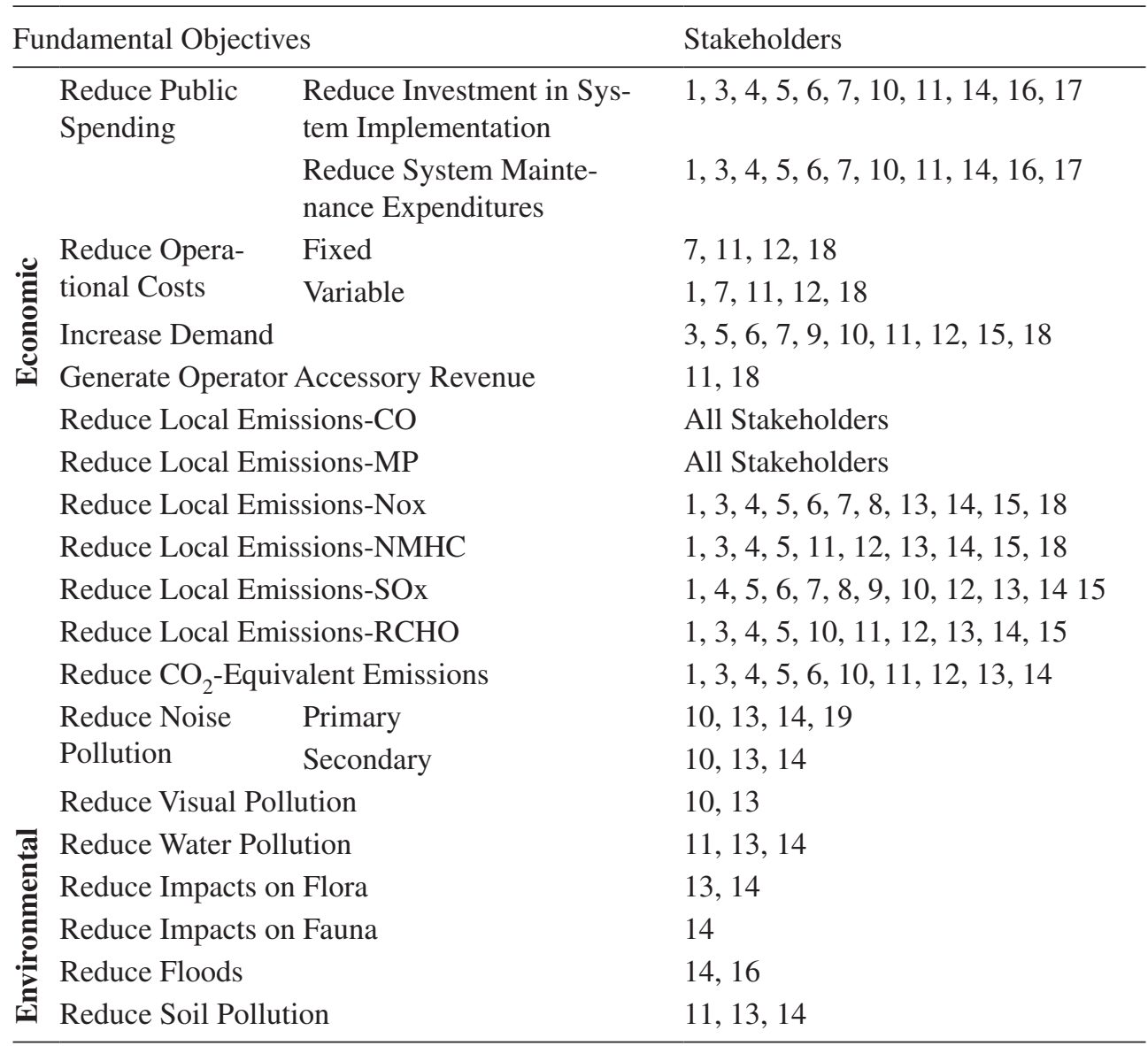

City Halls: 1-Santos, 3-Bertioga, 4-Cubatão, 5-São Vicente, 6-Praia Grande, 7-Itanhaém, 8-Mongagua, 9-Peruíbe; State Governments: 10-EMTU, 11-DERSA, 12-AGEM-BS, 13-CETESB-BS; Federal Government: 14-IBAMA; and Others: 15-Brazilian Cyclist Association (ABC), 16-Residents-Santos, 17-Public Transportation Users-Santos, 18-Private Transportation Operator-Piracicabana Bus Company/Mobility, 19-Residents-Bertioga, 20-Public Transportation Users-Bertioga

Step 6: In addition to the list of fundamental objectives, a hierarchy of objectives for each stakeholder was created during the interview.

Step 7: During the same interview, the hierarchy was presented to each stakeholder, who then validated it or requested changes. This was a way to save time, since many stakeholders were too busy to participate in a second interview.

Step 8: In the office, the facilitator analyzed all of the individual fundamental objective hierarchies to determine any common objectives, redundant objectives, or objectives that complement individual hierarchies. The end result was a hierarchy of fundamental objectives that needed to be validated by the stakeholders. 


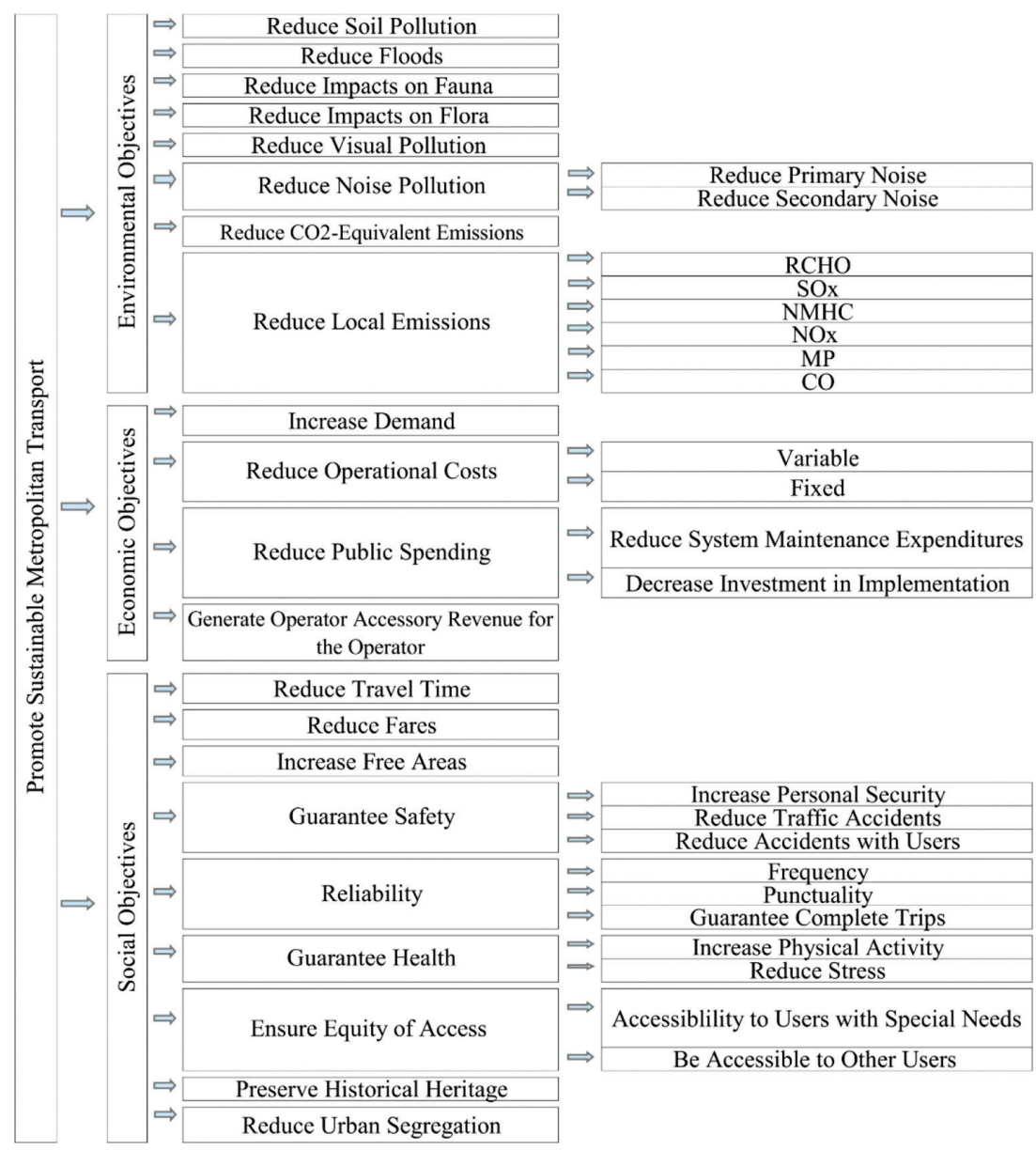

Figure 3: Hierarchy of joint fundamental objectives

Step 9: The result of this process is presented in Fig. 3, which represents the values expressed by all of the stakeholders in the region within the context of metropolitan transportation in the Baixada Santista.

In this step, the joint hierarchy was presented to the stakeholders individually. Their questions were answered and some provided suggestions; others simply validated the joint hierarchy. Stakeholders may also propose possible amendments, which makes a final conciliation meeting important. After the individual validations, a conciliation meeting was held at the headquarters of the Baixada Santista Metropolitan Agency. The conciliation meeting was led by the facilitator, and the stakeholders present included local government representatives from Santos (the seat of the region), from Praia Grande (the fastest growing city in terms of population), from the Baixada Santista Metropolitan Agency (a São Paulo state government agency that coordinates metropolitan planning), the Metropolitan Urban Transportation Company or EMTU (which is responsible for the planning and supervision of metropolitan transportation), and the Brazilian Cyclists Association or ABC (a non-governmental entity that advocates 
advances in non-motorized modes of transportation). During the meeting, the stakeholders' individual hierarchies and the joint hierarchy were presented in order to stimulate debate. After a discussion among the stakeholders, they validated the joint hierarchy with no changes to the final model. It is important to note that during the conciliation meeting the stakeholders took the initiative to consider the joint hierarchy and discuss options for improving the metropolitan system; intervention by the facilitator was not necessary for this purpose.

\section{DISCUSSION}

First, it is important to discuss how stakeholders are involved in the process. Of the 20 stakeholders determined for the region, 19 participated in the interviews. All became involved with the problem and even facilitated the other steps necessary for validation of the hierarchies. It is important to note that there were scheduling demands in nearly all cases, which made the process more time consuming; a lot of flexibility and commitment were required on the part of the facilitator in order for all of the interviews to be completed.

The interviews were long - approximately 90 minutes in duration. Thus, in the process of determining the objectives, it is essential that the facilitator stay focused on the topics associated with this metropolitan issue. Even with the presentation of a small initial text that establishes the context of a discussion on sustainable metropolitan transport, the stakeholders (and particularly those from the local city halls) at times tended to discuss local issues, a situation which should be avoided. In addition to the objectives, the interviews revealed a lack of integration between the stakeholders with regard to these metropolitan issues. Particularly, during the individual and joint hierarchy validation processes and before the conciliation meeting, the stakeholders involved expressed significant interest in the views of the other stakeholders, such as the other city hall representatives and the other sectors.

During the conciliation meeting, the joint hierarchy that had been validated on an individual level was presented, and a discussion about the objectives among the stakeholders began. There was a frank discussion on the subject, but no changes were made to the final hierarchy. The presentation of the hierarchy did, however, generate a series of dialogs on the difficulties of the metropolitan system, including proposals for improvement.

The main result of the application of the process to the Baixada Santista was a joint hierarchy with 39 fundamental objectives organized by environmental, economic, and social sustainability objectives. Of the total 39 objectives, 17 were social, 6 were economic, and 15 were environmental. The categories were found to have many points in common. One example is the local and global effect of gas emissions ( $\mathrm{CO}_{2}$ equivalent), an issue cited by almost all of the stakeholders. Other environmental objectives were identified by the more technical stakeholders from the environmental agencies, the EMTU, and the Greater Santos Area Highway Development Agency known as DERSA. In the case of social objectives, the stakeholders were also found to have many similar concerns, such as reducing travel time, reducing tariffs, having comfort, ensuring fair access in general, and ensuring fair access to users with special needs, all of which proved to be important points for metropolitan transportation planning. On the other hand, the preservation of historical heritage was noted only by the environmental agencies, since it is part of some of their environmental licensing processes in Brazil. The objective of reducing urban segregation was cited only by the EMTU, a state agency for the planning and supervision of metropolitan transportation. In economic terms, the main concerns are the reduction in public spending and the increase in demand, which again demonstrate how limited the resources for the sector are and how important the planning of sustainable metropolitan transport is. 


\section{CONCLUSIONS}

This study proposes a process for obtaining objectives from the various stakeholders involved in sustainable metropolitan transport that respects local situations and relies on interactions between these stakeholders, including the general public, in order to determine the fundamental values for the region under study and to add the stakeholders' views on sustainable transport. The general list of objectives also helps metropolitan transportation managers understand the strengths and weaknesses of the existing system in terms of sustainability; it is also a teaching tool for stakeholders and the facilitator, since these issues are often not discussed or analyzed with a depth that would reach the essence of the problems in this sector. The views are contrasting but, at the same time, complementary to the objectives of sustainability. During the final presentation of the joint hierarchy of objectives, the stakeholders' main comment was that it was complete and representative of their region.

It is important to note that not all of the stakeholders were formally trained in transportation issues and that few had any prior understanding of sustainability in the transportation sector. Nevertheless, the list of fundamental objectives generated was found to be comprehensive at all levels of sustainability and consistent with the literature on the subject. The process proposed herein proved to be adequate for determining the various stakeholders' objectives regarding the issues of sustainable transport. This fundamental step in the planning process allows customized and more appropriate proposals to be made based on these objectives. Application of the same process to other metropolitan areas both in Brazil and around the world is encouraged not only to verify its applicability but also to compare the fundamental objectives found. Although fundamental objectives may be similar, the path to determining them will allow metropolitan transportation planners to reflect on the search for more sustainable transport. Once the feasibility of the methodology has been demonstrated, future research may be able to examine the issue of freight transport.

\section{REFERENCES}

[1] Rahman, A.U., Urban sustainability through strategic planning: a case of metropolitan planning in Khulna city, Bangladesh. Journal of Urban Management, 5, pp. 16-22, 2016. https://doi.org/10.1016/j.jum.2016.06.001

[2] Lalehpour, M, Recognition of management structure and spatial planning in Tehran metropolitan area. Journal of Urban Management, 5, pp. 3-15, 2016. https://doi.org/10.1016/j.jum.2016.05.001

[3] Barandier, J.R., Niterói's central area urban redevelopment project: planning to achieve sustainable mobility in metropolitan area of Rio de Janeiro. Transportation Research Procedia, 25, pp. 3116-3128, 2017. https://doi.org/10.1016/j.trpro.2017.05.341

[4] Liu, L. \& Alain, L.H., Transport and land use interaction: a French case of suburban development in the Lille Metropolitan Area (LMA). Transportation Research Procedia, 4, pp. 120-139, 2014. https://doi.org/10.1016/j.trpro.2014.11.011

[5] Beiler, M.O., Organizational sustainability in transportation planning: evaluation of multi-jurisdictional agency collaboration. Journal of Transport Geography, 52, pp. 29-37, 2016.

https://doi.org/10.1016/j.jtrangeo.2016.02.013 
[6] EEA, 2006: Urban sprawl in Europe-The ignored challenge. Relatorio da Agencia Europeia do Ambiente, 10/2006.

[7] Goldman, T. \& Gorham, R., Sustainable urban transport: Four innovative directions. Technology in Society, 28, pp. 261-273, 2006. https://doi.org/10.1016/j.techsoc.2005.10.007

[8] Silva, A.N.R., Costa, M.S. \& Macedo, M.H. Multiple views of sustainable urban mobility: the case of Brazil. Transport Policy, 15(6), pp. 350-360, 2008. https://doi.org/10.1016/j.tranpol.2008.12.003

[9] Yedla, S. \& Shrestha, R.M., Multi-criteria approach for the selection of alternative options for environmentally sustainable transport system in Delhi. Transportation Research Part A, 37, pp. 717-729, 2003. https://doi.org/10.1016/s0965-8564(03)00027-2

[10] Jones, S., Tefe, M. \& Appiah-Opoku, S., Proposed framework for sustainability screening of urban transport projects in developing countries: a case study of Accra, Ghana. Transportation Research Part A, 49, pp. 21-34, 2013. https://doi.org/10.1016/j.tra.2013.01.003

[11] CERTU. Center for Studies on Networks, Transport, Town Planning and Public Buildings., Le Plan de Déplacements Urbains: Pour une intégration des politiques de mobilité. Mobilités et transports-outils et méthodes $n^{\circ} 1$, Septembre, 2012.

[12] Rupprecht Consult: Guidelines. Developing and Implementing a Sustainable Urban Mobility Plan, P. 8, Jan, 2014, available at: http://www.eltis.org/mobility-plans/ sump-concept (accessed 8 January 2018).

[13] Keeney, R.L., Value Focused Thinking: A Path to Creative Decision Making, Harvard University Press: Cambridge, 1992.

[14] Jeon, C.M. \& Amekudzi, A., Addressing sustainability in transportation systems: definitions, indicators, and metrics. Journal of Infrastructure Systems, 11, pp. 31-50, 2005. https://doi.org/10.1061/(asce)1076-0342(2005)11:1(31)

[15] Qureshi, I.A., Urban transport and sustainable transport strategies: a case study of Karachi, Pakistan. Tsinghua Science and Technology, 12(3), pp. 309-317, 2007. https://doi.org/10.1016/s1007-0214(07)70046-9

[16] Litman, T., Sustainable Transportation and TDM. Online TDM Encyclopedia. Victoria Transport Policy Institute, 2009, availbale at trb.org.br (Accessed 2 November 2017)

[17] Banister, D. The sustainable mobility paradigma. Transport Policy, 15, pp. 73-80, 2008. https://doi.org/10.1016/j.tranpol.2007.10.005

[18] Gössling, S., Urban transport justice. Journal of Transport Geography, 54, pp. 1-9, 2016.

https://doi.org/10.1016/j.jtrangeo.2016.05.002

[19] Tischler, S. \& Mailer, M., Sustainable mobility and living in alpine metropolitan regions. Transportation Research Procedia, 4, pp. 140-153, 2014. https://doi.org/10.1016/j.trpro.2014.11.012

[20] Pospischil, F. \& Mailer, M., The potential of cycling for sustainable mobility in metropolitan regions-the facts behind the success story of Innsbruck. Transportation Research Procedia, 4, pp. 80-89, 2014. https://doi.org/10.1016/j.trpro.2014.11.007

[21] Angel, S. \& Blei, A.M., The productivity of American cities: how densification, relocation, and greater mobility sustain the productive advantage of larger U.S. metropolitan labor markets. Cities, 51, pp. 36-51, 2016.

https://doi.org/10.1016/j.cities.2015.11.030 
[22] Wang, Y., Mishra, S., Ye, X., Li, L. \& Wu, B., The application of integrated multimodal metropolitan transportation model in urban redevelopment for developing countries. Transportation Research Procedia, 25, pp. 2990-3002, 2017. https://doi.org/10.1016/j.trpro.2017.05.378

[23] Jeon, C.M., Amekudzi, A.A. \& Guensler, R.L., Evaluating plan alternatives for transportation system sustainability: Atlanta Metropolitan Region. International Journal of Sustainable Transportation, 4(4), pp. 227-247, 2007. https://doi.org/10.1080/15568310902940209

[24] TAC. Transportation Association of Canada., Sustainable urban transportation initiatives in Canada. Presented at APEC Forum on Urban Transportation, Seoul, Korea, November 20-22, 1996.

[25] Shiftan, Y., Kaplan, S. \& Hakkert, S., Scenario building as a tool for planning a sustainable transportation system. Transportation Research D: Transport and Environment, 8(5), pp. 323-342, 2003. https://doi.org/10.1016/s1361-9209(03)00020-8

[26] Litman, T., Well Measured: Developing Indicators for Sustainable and Livable Transport Planning. Monograph Victoria Transport Policy Institute, 2012, available at http:// www.vtpi.org/wellmeas.pdf (accessed 1 November 2017)

[27] Nijkamp, P., Borzacciello, M.T., Ciuffo, B. \& Torrieri, F., Sustainable urban land use and transportation planning: a cognitive decision support system for the Napels metropolitan area. International Journal of Sustainable Transportation, 1, pp. 91-114, 2007. https://doi.org/10.1080/15568310601091981

[28] Litman, T., Reinventing Transportation-Exploring the Paradigm Shift Needed to Reconcile Transportation and Sustainability Objectives, Victoria Transport Policy Institute, 2003.

[29] Sagaris, L., Citizen participation for sustainable transport: the case os "Living City" in Santiago, Chile (1997-2012). Journal of Transport Geography, 41, pp. 74-83, 2014. https://doi.org/10.1016/j.jtrangeo.2014.08.011

[30] Nijkamp, P., Roads toward environmentally sustainable transport. Transportation Research Part A: Policy and Practice, 28A(4), pp. 261-271, 1994. https://doi.org/10.1016/0965-8564(94)90002-7

[31] Greene, D.L. \& Wegener, M., Sustainable transport. Journal of Transport Geography, 5(3), pp. 177-190, 1997. https://doi.org/10.1016/s0966-6923(97)00013-6

[32] Geurs, K. \& Van Wee, B., Backcasting as a tool to develop a sustainable transport scenario assuming emission reductions of 80-90\%. Innovation, 13(1), pp. 47-62, 2000. https://doi.org/10.1080/135116100111658

[33] Steg, L. \& Gifford, R., Sustainable transportation and quality of life. Journal of Transport Geography, 13, pp. 59-69, 2005. https://doi.org/10.1016/j.jtrangeo.2004.11.003

[34] Belton, V. \& Stewart, T.J., Multiple Criteria Decision Analysis: An Integrated Approach, Kluwer Academic Publishers: Norwell, 2002.

[35] Galves, M.L., Structuring Decision Situations: A Brief Overview, Advances in Multicriteria Decision Aid, Brest, França, 2005.

[36] Montibeller, G., Franco, L.A., Lord, E. \& Iglesias, A., Structuring resource allocation decisions: a framework for building multi-criteria portfolio models with area-grouped options. European Journal of Operational Research, 199, pp. 846-856, 2009.

https://doi.org/10.1016/j.ejor.2009.01.054 
[37] Roy, B. \& Bouyssou, D., Aide multicritère à la décision: méthodes et cas. Paris: Econômica, 1993.

[38] Barros, A.J.S. \& Lehfeld, N.A.S., Fundamentals of the Scientific Method (Original Name: Fundamentos da Metodologia Científica), Prentice Hall: São Paulo, 2007.

[39] Brasil. Ministry of Planning, Budget, and Management (Ministério do Planejamento, Orçamento e Gestão). Resolution No. 2 from 26 August, 2017. Resident Populations by State (Original Name: População residente segundo as unidades da Federação); The Brazilian Government's Official Gazette (Diário Oficial da União), p. 98, 28 August, 2014, available at https://www.jusbrasil.com.br/diarios/75661110/dou-secao-1-28-082014-pg-98 (accessed 5 October 2016)

[40] AGEM-The Greater Santos Metropolitan Agency, Technical Studies, Surveys, Diagnoses, and Guidelines for Creating a Plan for a Bike Lane System in the Greater Santos Metropolitan Area, or the Baixada Santista, 2006. 